\title{
RESEARCH ON A NEW DOUBLE-WALL STEEL INSULATION SILO WITH MULTIPLE BOLTED JOINTS: PART II, EXPERIMENTAL VERIFICATION
}

\author{
Gan Tang ${ }^{1,2}$, Lingfeng Yin ${ }^{2, *}$, Xiaoming Guo ${ }^{2}$ and Haibin Lai ${ }^{2}$ \\ ${ }^{1}$ Department of Civil Engineering, Nanjing University of Aeronautics and Astronautics, \\ YuDao Street 29, Nanjing, China, 210016 \\ ${ }^{2}$ School of Civil Engineering, Southeast University, SiPaiLou 2, Nanjing, China, 210096 \\ *(Corresponding author: Email: eking@seu.edu.cn)
}

Received: 26 September 2011; Revised: 21 January 2012; Accepted: 28 January 2012

\begin{abstract}
An experimental model of a double-wall steel insulation silo with multiple bolted joints is designed. The experiment results and the finite element results are compared and analyzed, and the following conclusions are reached. The cooperation between the internal and external walls is outstanding. Among the six proposed models, A3, A4 and A5 present almost the same results, which satisfyingly coincide with the experiment results. The horizontal pressure is mainly resisted by the internal wall under tension during the whole loading process. Before the force $\mathrm{P}$ reaches $\mathrm{P}_{\mathrm{u} \text {-in, }}$, the vertical friction force is carried by both the internal and external walls. When the force $\mathrm{P}$ reaches $\mathrm{P}_{\mathrm{u} \text {-in }}$, the internal wall at the area between the first external ring beam and the supports shows a sudden elastic-plastic buckling. After that, the external wall bears more and more vertical friction force, then it also shows an elastic-plastic buckling at the same area. Finally, the walls at this area are destroyed and the model loses the bearing capability.
\end{abstract}

Keywords: Steel insulation silo; double-wall; experiment; cooperation between the internal and external walls; elastic-plastic buckling

\section{INTRODUCTION}

In the former paper [1], a new double-wall steel insulation silo with multiple bolted joints for grain storage is proposed. The silo employs the planar thin-walled steel plate as the internal wall, and the continuous ladder-shaped profiled plate as the external wall. The cavity between the internal and external walls is filled with insulation material. The silo utilizes specifically designed bolt connections to connect the internal and external walls. The silo is environmentally friendly, featured with simple structure and high integrity. The design of the silo enables it to save energy and steel consumption with a pleasant appearance. An experimental silo model is studied and the results show that the horizontal pressure from the grains is resisted by the internal wall under tension, and that the vertical friction force is mainly carried by both the external and internal walls. The stability of the internal wall is effectively provided by the external wall. The stiffness of the connection area must be appropriately simulated and the selection of connection model between the internal and external walls has a significant impact on the structural performance of the silo. Based on the above, this paper designs the experimental silo model and examines its structural behavior. The experiment results and the finite calculation results are compared and analyzed to make an optimal selection of connection model between the internal and external walls. The bearing patterns during the whole loading process are also researched.

Brown et al. described the design, conduct and verification of a series of experiments on a square planform funnel-flow unstiffened steel silo containing free-flowing granular solids [2]. The results of model tests with a steel silo at the University of Karlsruhe are summarised by Tejchman and Ummenhofer [3]. The results of five tests on cone-cylinder-skirt-ring junctions under simulated bulk solid loading were presented by Zhao and Teng [4] and the finite element modeling of the experiments was given in the companion paper [5]. Yin and Huang performed dynamic experiments of thin-walled silo models on different foundations [6]. Zhang and Shu conducted a discharging 
experiment for floor-type steel silo model, in which time-dependent stresses of silo walls with 8 different discharge opening diameters and positions were studied [7]. The plans and results of the above researches have provided valuable insights into the design and study in this paper.

\section{MODEL EXPERIMENT OF STEEL INSULATION SILO}

\subsection{Model Design and Manufacture}

The internal diameter and the height of the experimental silo model are $500 \mathrm{~mm}$ and $1200 \mathrm{~mm}$ respectively. The spacing between the internal and external walls is $25 \mathrm{~mm}$. Three external ring beams are set at the height of $250 \mathrm{~mm}, 750 \mathrm{~mm}$ and $1105 \mathrm{~mm}$ respectively. The external wall uses the YX 35-125-750 profiled steel plate, and the internal wall is a circular plate, the thickness of both walls $1 \mathrm{~mm}$. The 8 -mm-diameter double-head bolts that connect the internal and external walls are placed with the vertical spacing of $100 \mathrm{~mm}$ and are evenly spaced around a circle. The internal wall, external wall and external ring beams are all spliced by the high-strength bolts. Dry yellow sand of diameter less than $0.25 \mathrm{~mm}$ is used to replace the grains. To avoid leaking of the sand, this design employs a bottom plate of diameter $640 \mathrm{~mm}$ for the experimental silo model. 14 steel angles are welded by one leg on the bottom plate. The other legs are between the internal and the external walls and are connected with them by three rows of bolts. The completed experimental silo model is shown in Figure 1.

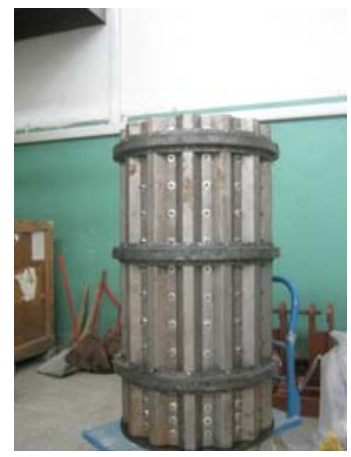

(a) Exterior

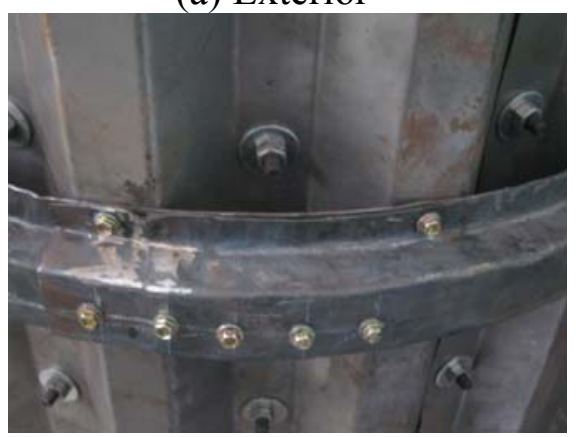

(c) External Ring Beam

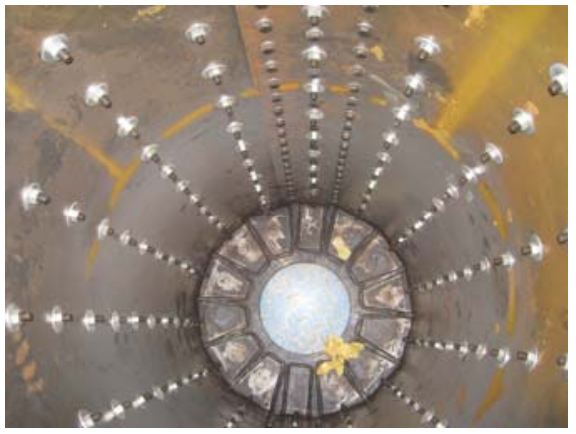

(b) Interior

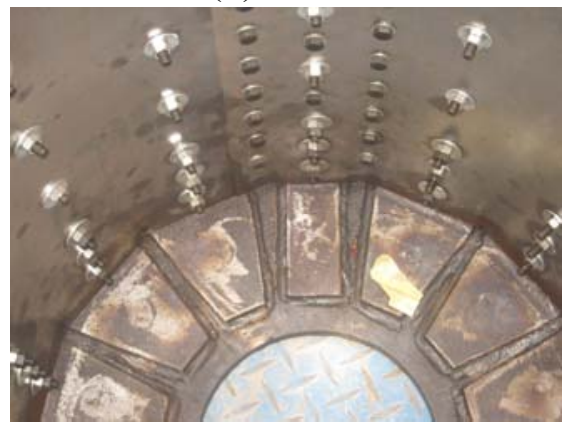

(d) Bottom Plate and Steel Angles

Figure 1. The Completed Experimental Silo Model

\subsection{Basic material properties}

The screened sand is quickly dried in a drier. The average gravity density of the sand $\gamma=1.5108 \times 10^{4} \mathrm{~N} / \mathrm{m}^{3}$ is obtained after the sand volume and quality are measured by a graduated cylinder and electronic balance. The average internal friction angle of the sand $\phi=25.46^{\circ}$ is obtained by a direct shear apparatus. 
From the material experiments by an universal testing machine, the elastic modulus of steel plate is obtained as $E=1.90 \times 10^{5} \mathrm{MPa}$, the yield strength $f_{y}=195 \mathrm{MPa}$, the ultimate strength $f_{u}=247 \mathrm{MPa}$, the initial yield strain $\varepsilon_{y}=1.0263 \times 10^{-3}$, the strain at initial strengthening $\varepsilon_{s t}=4.292 \times 10^{-3}$ and the ultimate strain $\varepsilon_{u}=9.292 \times 10^{-3}$.

\subsection{Loading and Measurement Plans}

(1) Loading Plan

The sand loads are too small to destroy the silo or cause an obvious strain of the silo walls [1]. Therefore, the original loads from the sand are ignored and a force transmission device, which is composed of an upper plate, a steel tube and a lower plate, is installed above the model to evenly apply the force $\mathrm{P}$ from the press machine to the sand in the model, as shown in Figure 2.

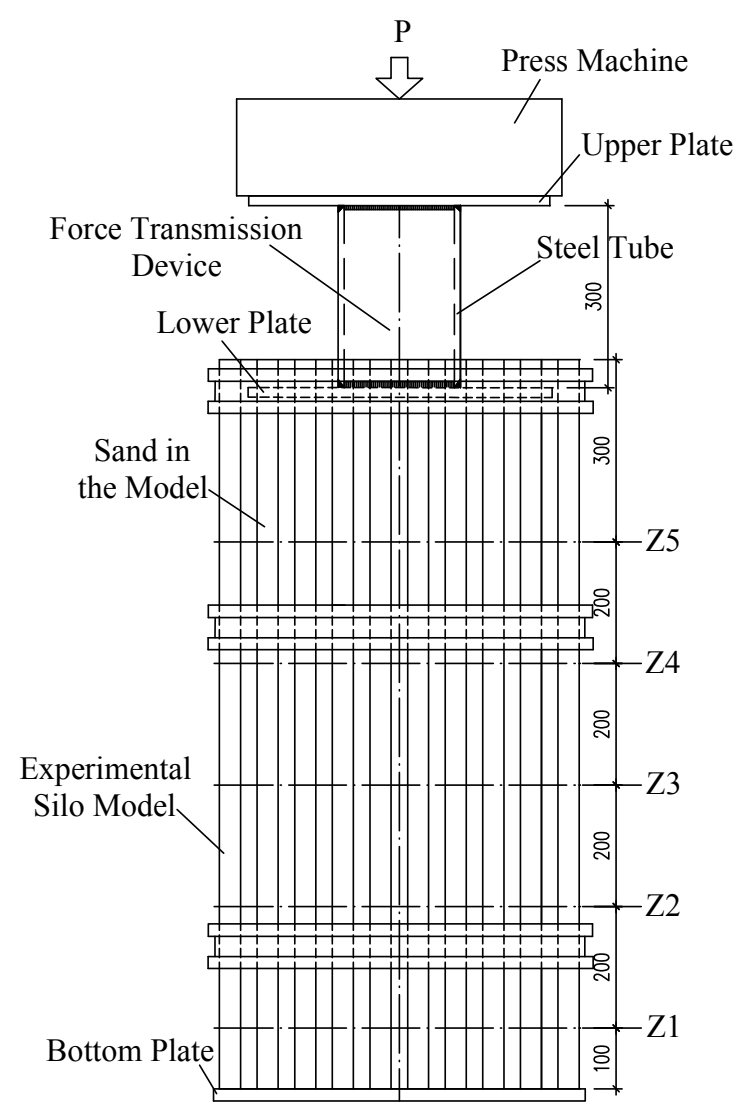

Figure 2. Loading Plan

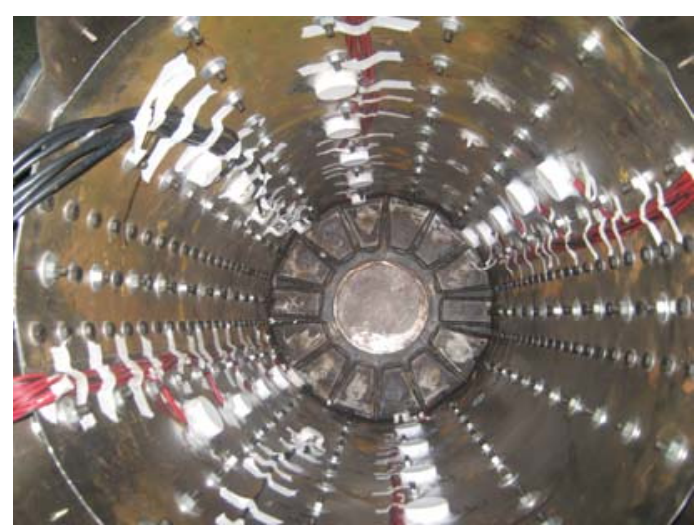

Figure 3. Protection of Pressure Cells and Strain Gauges 


\section{(2) Horizontal Pressure Measurement}

Pressure cells are used to measure the horizontal pressure from the sand to the internal wall. The pressure cells are placed at $\mathrm{Z1}$ to $\mathrm{Z5}$, the same heights as the strain observation points. Plastic boxes are used to fix and protect the pressure cells during the loading process (Figure 3). Glass adhesive is used to seal the plastic box to avoid the leaking-in of the sand that can interfere with data collection.

\section{(3) Strain Measurement}

Along the circles at $\mathrm{Z1}$ to $\mathrm{Z5}$, right angle strain rosettes are attached to the interior surface of the internal wall to measure the horizontal and vertical strains, as shown in Figure 4(a). Similarly, in Figure 4(b), vertical strain gauges are attached to the exterior surface of the external wall. Note that some vertical strain gauges are replaced with right angle strain rosettes at Z3 to Z5, and that the positions of some strain observation points on the external wall are slightly adjusted due to the existence of the bolts.

\section{(4) Deformation Measurement}

A displacement meter is set at every $200 \mathrm{~mm}$ along the vertical direction to measure the deformation of the external wall and a displacement meter is set on each of the three external ring beams.

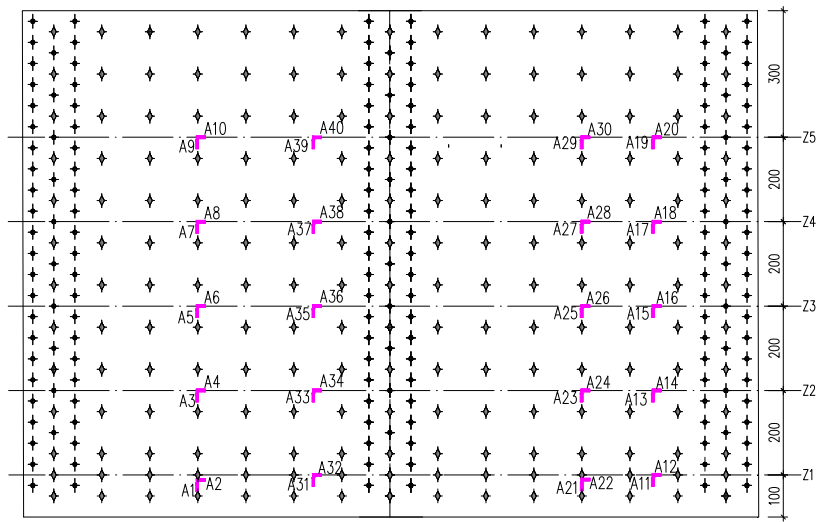

(a) Internal Wall

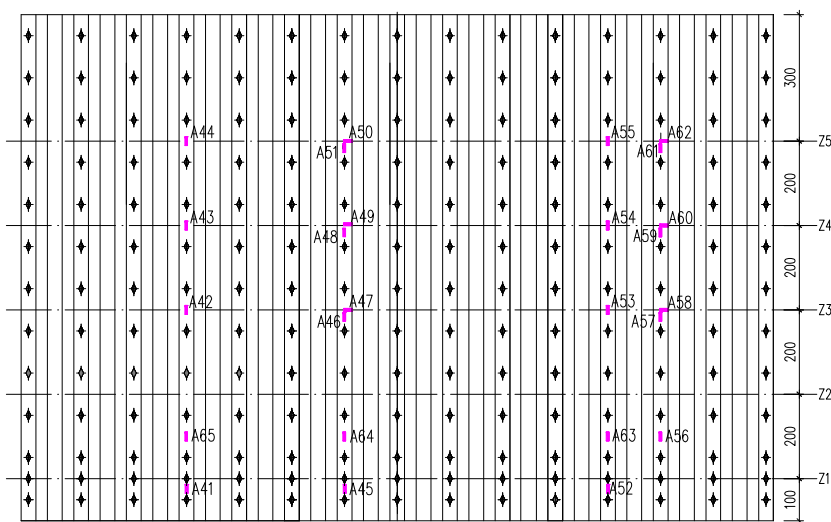

(b) External Wall

Figure 4. Strain Observation Points on the Internal and External Walls

\subsection{Experiment Process and Results}

First, the strain gauges, strain rosettes and pressure cells are connected by wires to two DH3816 static strain collecting instruments and their proper operation states are checked. Then the dried yellow sand is charged into the model. After that, the force transmission device is hoisted and then placed on the sand. It has to be checked that the wires are not pressed by the force transmission device. The model is lifted onto a steel platform. A pressure sensor between the press machine and force transmission device and the displacement meters are placed and then connected to the static strain collecting instruments. For the site ready for the experiment, see Figure 5.

An actual loading is performed level by level after three pre-loadings, each level increasing $5 \mathrm{KN}$ from the previous level. The strain, deformation, force $\mathrm{P}$ and horizontal pressure at each level are synchronously collected. 
A slight noise, which is created by the sand being squeezed against the internal wall, is heard at the initial loading stage. As the force $\mathrm{P}$ increases, the horizontal and vertical strains of the internal wall are increased apparently, and so is the vertical strain of the external wall, yet the horizontal strain of the external wall is not noticeably increased. When the force $\mathrm{P}$ is increased to around $300 \mathrm{KN}$, slight wrinkles occur on the external wall between first external ring beam and the supports. With the force P increased further, the wrinkled area expands. When the force P reaches $410 \mathrm{KN}$, the model loses its bearing capacity. The failure mode is shown in Figure 6 and the specific data is given in section 3.2 and 3.3 .

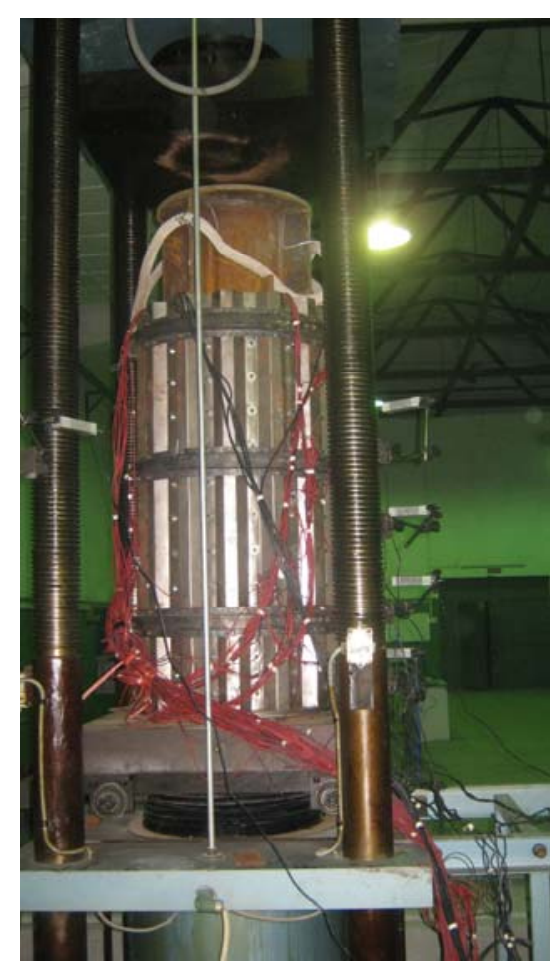

Figure 5. Experiment Site

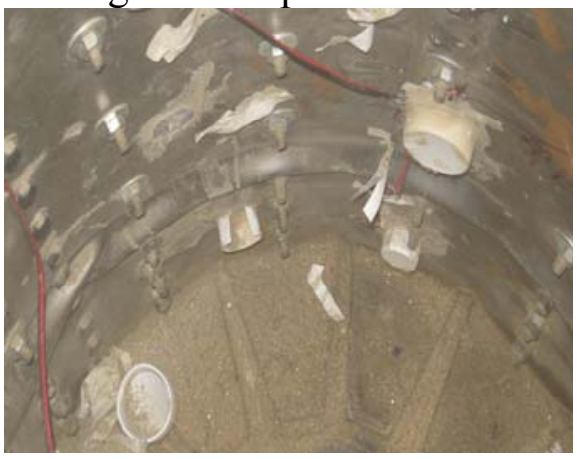

(a) Internal Wall

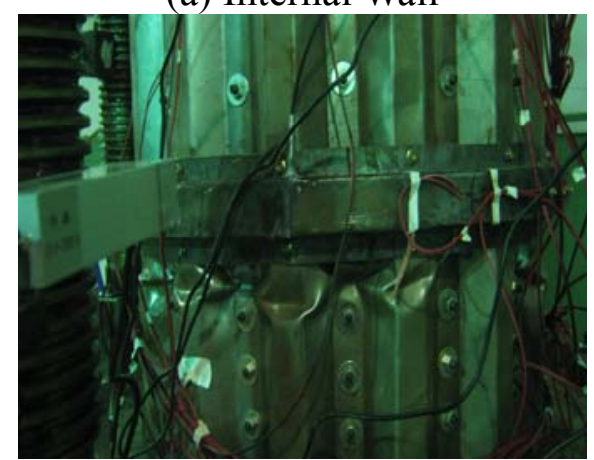

(b) External Wall

Figure 6. Failure Mode of the Experimental Silo Model 


\section{NONLINEAR FINITE ELEMENT ANALYSIS}

\subsection{Finite Element Modeling}

To compare with the experiment results, the geometrical and material nonlinear analysis of the FE model is carried out, where the modeling of the internal wall, external wall, external ring beams, boundary conditions and the connection models between the internal and external walls are the same as in Ref.[1] while the material constitutive relation and loading mode are obtained from the experiment.

(1) Material Constitutive Relation

A trilinear model is achieved from the simplification of results of the material experiment, as shown in Figure 7, where $f_{y}=195 \mathrm{MPa} ; f_{u}=247 \mathrm{MPa}, \varepsilon_{y}=1.0263 \times 10^{-3}, \varepsilon_{s t}=4.292 \times 10^{-3}$, $\varepsilon_{u}=9.292 \times 10^{-3}$.

\section{(2) Loading Mode}

During the loading process, the horizontal pressures at $\mathrm{Z1}$ to $\mathrm{Z} 5$ of the internal wall, measured by the pressure cells, basically take the form of linear growth, as shown in Figure 8. To facilitate calculation, linear regression is used for the data in Figure 8 and the results in Figure 9 are obtained, based on which the horizontal pressures at other heights are achieved by linear interpolation. The vertical friction force is the horizontal pressure (at the same height) multiplied by the friction coefficient $\mu$ and $\mu=0.4$. In the FE model, all the loads are applied to the nodes of the internal wall.

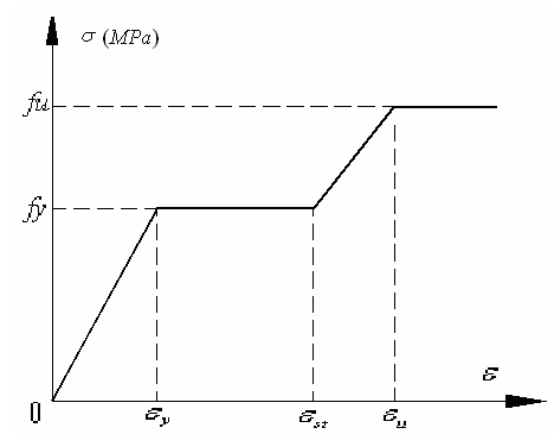

Figure 7. Material Constitutive Relation

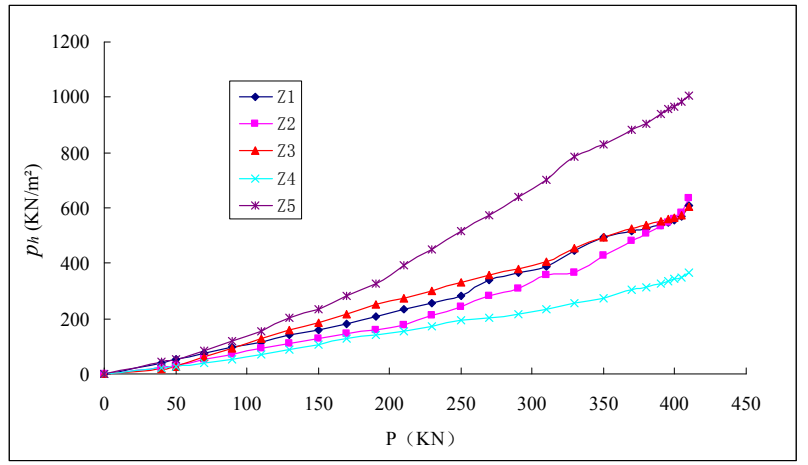

Figure 8. Horizontal Pressures by Pressure Cells 


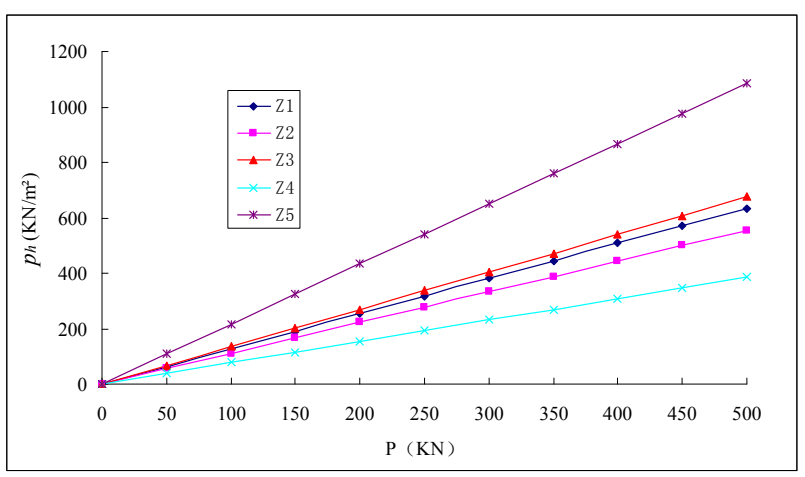

Figure 9. Horizontal Pressures after Linear Regression

\subsection{Results Analysis}

Nonlinear analysis of six connection models A1 to A6 (Ref.[1]) are conducted. The typical values of the force $\mathrm{P}$ are listed in Table 1 , where $\mathrm{P}_{\mathrm{y} \text {-in }}$ and $\mathrm{P}_{\mathrm{y} \text {-ex }}$ are the respective values of the force $\mathrm{P}$ when the maximum Mises stresses of the internal and external walls reach the yield strength (195 $\mathrm{MPa}), \mathrm{P}_{\mathrm{u}-\mathrm{in}}$ and $\mathrm{P}_{\mathrm{u}-\mathrm{ex}}$ the respective values of the force $\mathrm{P}$ when the maximum Mises stresses of the internal and external walls reach the ultimate strength $(247 \mathrm{MPa})$; “-_" indicates that the ultimate strength is not reached; $\mathrm{P}_{\max }$ is the value of the force $\mathrm{P}$ when the model loses its bearing capacity. The typical Mises stress distributions of the internal and external walls are shown in Figure 10. The typical maximum deformations are shown in Table 2.

In Table $1, \mathrm{P}_{\mathrm{y} \text {-in }}$ and $\mathrm{P}_{\mathrm{y} \text {-ex }}$ of the experiment are the respective values of the force $\mathrm{P}$ when the maximum stresses measured on the internal and external walls reach the yield strength. Given the limited number of strain observation points, the experiment results cannot reflect the entire strain distribution of the internal and external walls, especially that of the stress concentration region. Hence, $\mathrm{P}_{\mathrm{y} \text {-in }}$ and $\mathrm{P}_{\mathrm{y}-\mathrm{ex}}$ of the experiment are larger than the actual values. For the same reason, $\mathrm{P}_{\mathrm{u}-\mathrm{in}}$ and $\mathrm{P}_{\mathrm{u} \text {-ex }}$ of the experiment cannot be determined but it does not indicate that the maximum Mises stresses of the internal and external walls do not reach the ultimate strength during the loading. However, $\mathrm{P}_{\max }$ of the experiment is an actual value.

Table 1. Typical Values of Force $\mathrm{P} / \mathrm{kN}$

\begin{tabular}{cccccccc}
\hline & $\mathrm{A} 1$ & $\mathrm{~A} 2$ & $\mathrm{~A} 3$ & $\mathrm{~A} 4$ & $\mathrm{~A} 5$ & $\mathrm{~A} 6$ & Experiment \\
\hline $\mathrm{P}_{\text {y-in }}$ & 180.0 & 150.0 & 160.0 & 160.0 & 160.0 & 290.0 & $\mathbf{2 0 5 . 0}$ \\
$\mathrm{P}_{\mathrm{y}-\mathrm{ex}}$ & 200.0 & 280.0 & 225.0 & 220.0 & 220.0 & 360.0 & $\mathbf{3 1 0 . 0}$ \\
$\mathrm{P}_{\mathrm{u}-\mathrm{in}}$ & - & - & 324.0 & 322.8 & 336.9 & 472.8 & - \\
$\mathrm{P}_{\mathrm{u}-\mathrm{ex}}$ & - & - & 418.8 & 414.9 & 417.1 & 488.1 & - \\
$\mathrm{P}_{\max }$ & 282.1 & 311.1 & 434.0 & 433.6 & 433.7 & 488.1 & 410.0 \\
\hline
\end{tabular}




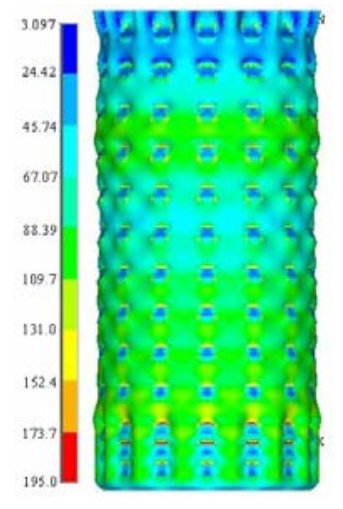

(a) A2's Internal Wall at $\mathrm{P}_{\mathrm{y} \text {-in }}$

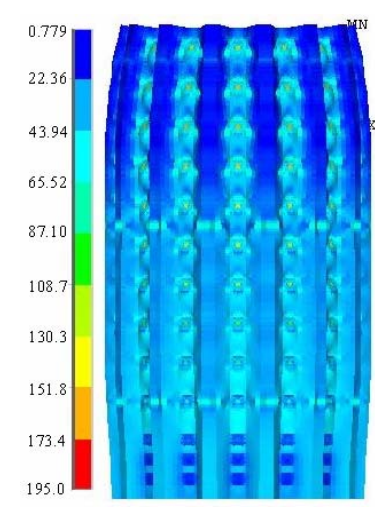

(b) A1's External Wall at $\mathrm{P}_{\mathrm{y} \text {-ex }}$

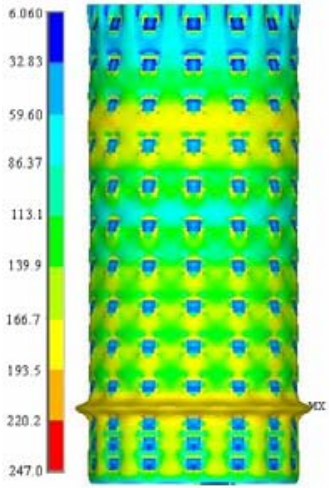

(c) A4's Internal Wall at $\mathrm{P}_{\mathrm{u} \text {-in }}$

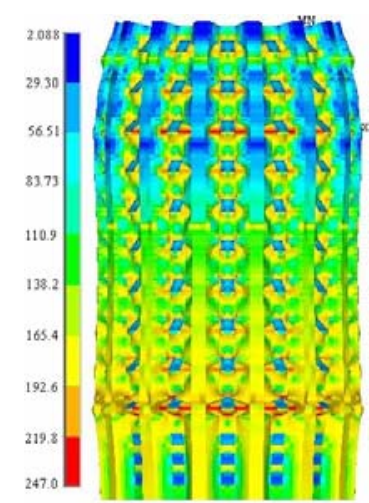

(d) A6's External Wall at $\mathrm{P}_{\mathrm{u} \text {-ex }}$ and $\mathrm{P}_{\max }$

Figure 10. Typical Mises Stress Distribution of the Silo Walls (MPa)

Table 2. Typical Maximum Deformations (mm)

\begin{tabular}{cccccccccccccc}
\hline & \multicolumn{4}{c}{$\mathrm{P}_{\mathrm{y}-\mathrm{in}}$} & \multicolumn{4}{c}{$\mathrm{P}_{\mathrm{y} \text {-ex }}$} & \multicolumn{4}{c}{$\mathrm{P}_{\max }$} \\
Models & \multicolumn{2}{c}{ Internal Wall } & \multicolumn{2}{c}{ External Wall } & \multicolumn{2}{c}{ Internal Wall } & \multicolumn{2}{c}{ External Wall } & \multicolumn{2}{c}{ Internal Wall } & External Wall \\
& Circular & Vertical & Circular & Vertical & Circular & Vertical & Circular & Vertical & Circular & Vertical & Circular & Vertical \\
\hline A1 & 0.012 & -0.334 & 0.026 & -0.119 & 0.013 & -0.372 & 0.028 & -0.133 & 0.018 & -0.544 & 0.040 & -0.194 \\
A2 & 0.011 & -0.241 & 0.023 & -0.119 & 0.020 & -0.457 & 0.044 & -0.227 & 0.022 & -0.523 & 0.050 & -0.260 \\
A3 & 0.011 & -0.248 & 0.025 & -0.133 & 0.016 & -0.357 & 0.036 & -0.192 & 0.068 & -1.748 & 0.432 & -0.875 \\
A4 & 0.011 & -0.241 & 0.024 & -0.129 & 0.015 & -0.332 & 0.033 & -0.178 & 0.068 & -1.727 & 0.423 & -0.855 \\
A5 & 0.011 & -0.238 & 0.024 & -0.130 & 0.015 & -0.328 & 0.033 & -0.180 & 0.068 & -1.753 & 0.480 & -0.896 \\
A6 & 0.007 & -0.337 & 0.045 & -0.318 & 0.009 & -0.425 & 0.057 & -0.399 & 0.041 & -0.952 & 0.195 & -0.913 \\
\hline
\end{tabular}

It can be seen from Table 1, Table 2 and Figure 10 that:

1) The bearing processes of the six models are similar because the material constitutive relation, simulation of silo walls and ring beams, boundary conditions, loading mode and finite element analysis are identical. At the initial loading stage, the circumferential outward expansion is observed and obvious stress concentration is seen at the support area and the connection area between the washers and the walls. With the force P increasing, the maximum Mises stress of the internal wall reaches the yield strength and then that of the external wall does. As the force $\mathrm{P}$ is further increased, the yield area of the internal wall gradually expands, especially the area near Z5 and the area between the first external ring beam and the supports, then a sudden buckling at the latter area occurs. After that, at the area between the first external ring beam and the supports in all six models except A1 and A2, the maximum Mises stress of the internal wall rapidly reaches the ultimate strength, and the yield area of the external wall further expands and then a buckling also occurs, next, the maximum Mises stress of the external wall reaches the ultimate strength. Finally, the walls at this area are destroyed and the model loses the bearing capability.

2) The typical values of the force $P$ of the six models vary significantly. $P_{y-i n}$ of A1 to A5 are similar but much smaller than that of A6. The differences among $\mathrm{P}_{\mathrm{y} \text {-ex }}$ of A1 to A5 are enlarged and $\mathrm{P}_{\mathrm{y} \text {-ex }}$ of A1 to A5 are also much smaller than that of A6. $\mathrm{P}_{\mathrm{u} \text {-in }}$ and $\mathrm{P}_{\mathrm{u} \text {-ex }}$ of $\mathrm{A} 1$ and $\mathrm{A} 2$ do not exist while $\mathrm{P}_{\mathrm{u} \text {-in }}$ and $\mathrm{P}_{\mathrm{u} \text {-ex }}$ of $\mathrm{A} 3$ to $\mathrm{A} 5$ are much smaller than that of A6. $\mathrm{P}_{\max }$ of A1 is the smallest, $\mathrm{P}_{\max }$ of A6 the largest, and $\mathrm{P}_{\max }$ of $\mathrm{A} 2, \mathrm{~A} 3, \mathrm{~A} 4$ and $\mathrm{A} 5$ are in between. 
$\mathrm{P}_{\max }$ of $\mathrm{A} 1$ and $\mathrm{A} 2$ are much smaller than $\mathrm{P}_{\max }$ of the experiment due to that they do not take into full consideration the stiffness of the connection area. A6 ensures the deformation consistency of the coupled nodes of the internal and external walls, which overestimates the cooperation between the internal and external walls, so $\mathrm{P}_{\max }$ of $\mathrm{A} 6$ exceeds $\mathrm{P}_{\max }$ of the experiment by about $20 \%$ and $\mathrm{P}_{\mathrm{y} \text {-in }}$ and $\mathrm{P}_{\mathrm{y} \text {-ex }}$ are larger than those of the experiment. The differences among all the typical values of the force $\mathrm{P}$ of $\mathrm{A} 3, \mathrm{~A} 4$ and $\mathrm{A} 5$ are insignificant. $\mathrm{P}_{\max }$ of $\mathrm{A} 3, \mathrm{~A} 4$ and $\mathrm{A} 5$ differ slightly from $\mathrm{P}_{\max }$ of the experiment (less than $6 \%$ ), and $\mathrm{P}_{\mathrm{y} \text {-in }}$ and $\mathrm{P}_{\mathrm{y}-\mathrm{ex}}$ of $\mathrm{A} 3, \mathrm{~A} 4$ and $\mathrm{A} 5$ are fairly reasonable. Therefore, $\mathrm{A} 3$, A4 and A5 can effectively reflect the cooperation between the internal and external walls.

3) The overall stress distributions and deformation characteristics of the six models under typical values of the force $\mathrm{P}$ are similar due to their similar bearing processes, but the details vary. Before the force $\mathrm{P}$ reaches $\mathrm{P}_{\mathrm{y}-\mathrm{in}}$, the differences among the circular stresses and deformations of $\mathrm{A} 1$ to $\mathrm{A} 5$ are insignificant while the differences among the vertical values are significant, however, both circular and vertical values are significantly different from those of A6. After the force P exceeds

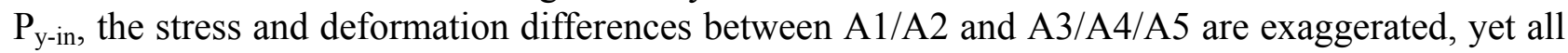
the stresses and deformations of the five models still differ greatly from those of A6. During the whole loading process, the stresses and deformations of A3, A4, and A5 are almost the same.

\subsection{Further Comparison between A3 Results and Experiment Results}

The A3 results and experiment results are further compared as shown in Figure 13 and 14.

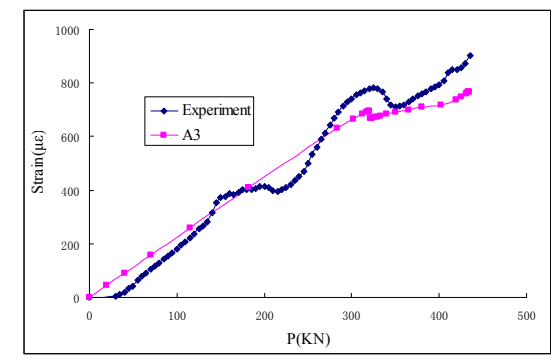

(a) Horizontal Strain of the Internal Wall at Z3

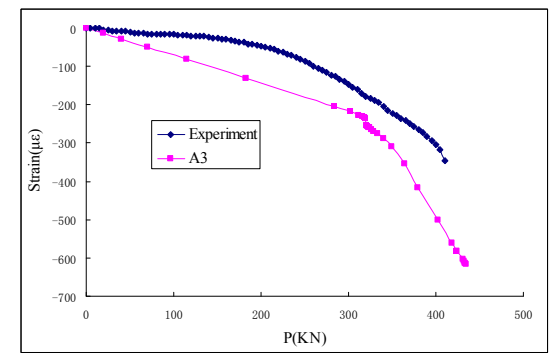

(d) Vertical Strain of the External Wall at Z5

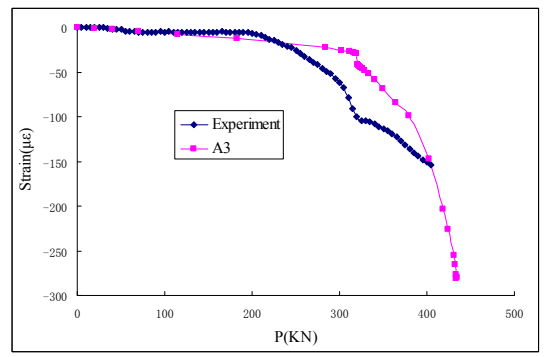

(b) Horizontal Strain of the External Wall at Z3

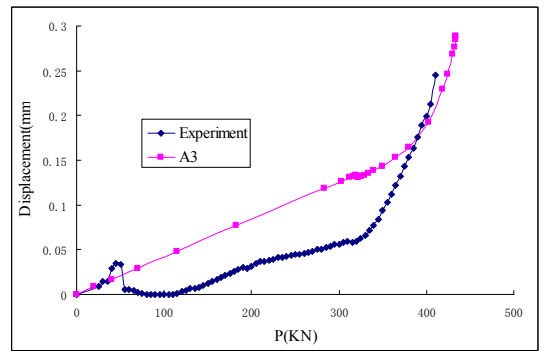

(e) Circular Deformation of the External Wall $50 \mathrm{~mm}$ above $\mathrm{Z2}$

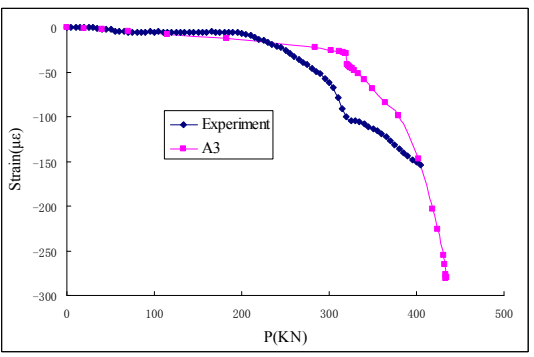

(c) Horizontal Strain of the External Wall at Z3

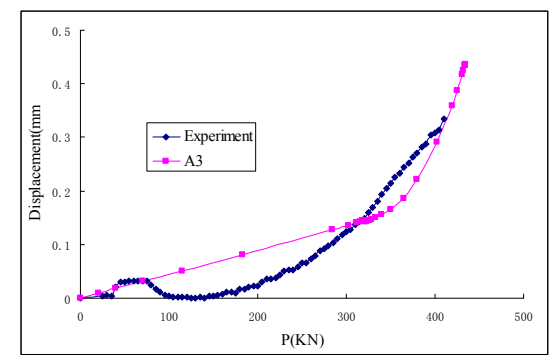

(f) Circular Deformation of the External Wall $50 \mathrm{~mm}$ below Z5

Figure 13. Comparison between A3 Results and Experiment Results 


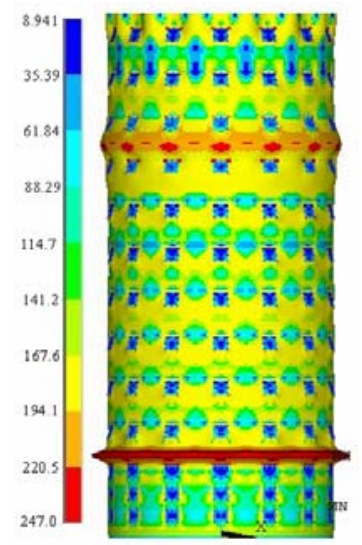

(a) Internal Wall

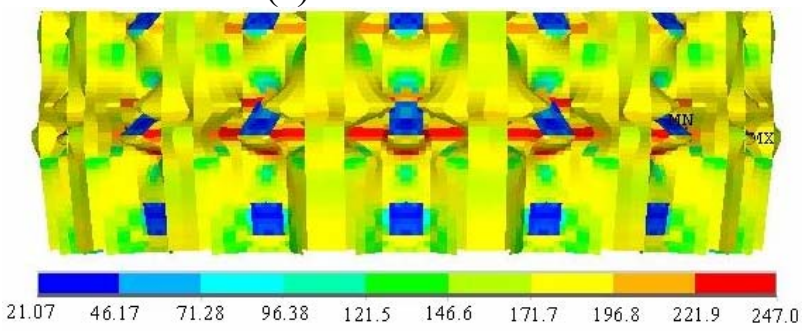

(b) External Wall (Local)

Figure 14. Failure Mode of A3

From the results in Figure 6, Figure 13 and Figure 14 it is worth noting that:

1) During the loading process, both the internal and external walls generally undergo circular tensions and vertical pressures. The vertical strain of the external wall is smaller than that of the internal wall. Due to the existence of the external ring beams, local area of the external wall undergoes a circular pressure.

2) The strain, deformation, failure mode of A3 are consistent with those of the experiment, indicating that $\mathrm{A} 3$ is a reasonable connection model.

\subsection{Bearing Patterns during the Loading Process}

Some results of A3 are obtained to examine the bearing patterns of the internal and external walls during the loading process, as shown in Figure 15 and Figure 16.

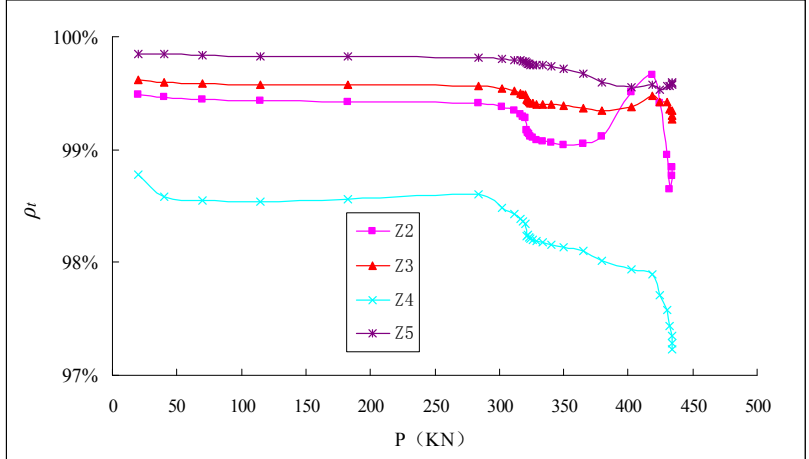

Figure 15. $\mathrm{P}-\rho_{t}$ Curves

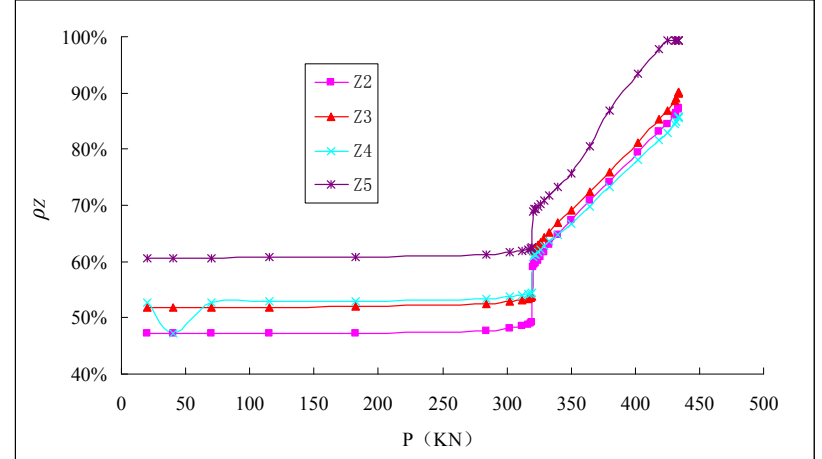

Figure 16. $\mathrm{P}-\rho_{Z}$ Curves

Note: for the definition of $\rho_{t}$ and $\rho_{Z}$, refer to Ref.[1] 
It can be indicated from Figure 15 and 16 that:

1) During the loading process, the pattern of resisting the horizontal pressure remains the same, where the horizontal pressure is mainly resisted by the internal wall under tension while the external wall does not resist much of the pressure. $\rho_{t}$, the bearing efficiency of the horizontal pressure, exceeds $97 \%$ at each height during the loading process. All the $\rho_{t}$ increase slightly along the upward direction of the silo, except that at Z4, where the hoop force of the external wall $N_{t, O}$ is slightly greater as affected by the external ring beam. $\rho_{t}$ at each height remains unchanged before the force $\mathrm{P}$ reaches $\mathrm{P}_{\mathrm{u} \text {-in }}$, after that, it slightly drops.

2) Before the force $\mathrm{P}$ reaches $\mathrm{P}_{\mathrm{u} \text {-in, }}, \rho_{Z}$, the bearing efficiency of the vertical friction force, basically remains unchanged at each height. All the $\rho_{Z}$ increase slightly along the upward direction of the silo, the values between $47 \%$ and $63 \%$. These indicate that the pattern of carrying the vertical friction force remains the same, where the vertical friction force is carried by both the internal and external walls. When the force $\mathrm{P}$ reaches $\mathrm{P}_{\mathrm{u}-\mathrm{in}}, \rho_{Z}$ sees a dramatic increase because a sudden elastic-plastic buckling of the internal wall sharply decreases its capacity of carrying the vertical friction force. After that, the external wall bears more and more vertical friction force, thus $\rho_{Z}$ increasing sharply.

3) Compared with Ref. [1], in this paper, the increasing rate of $\rho_{Z}$ along the upward direction of the silo at the initial loading stage is smaller. The major reason is that the loading modes in the two papers are different, as shown in Figure 17. Thus the loading mode has a great impact on the bearing pattern of the vertical friction force.

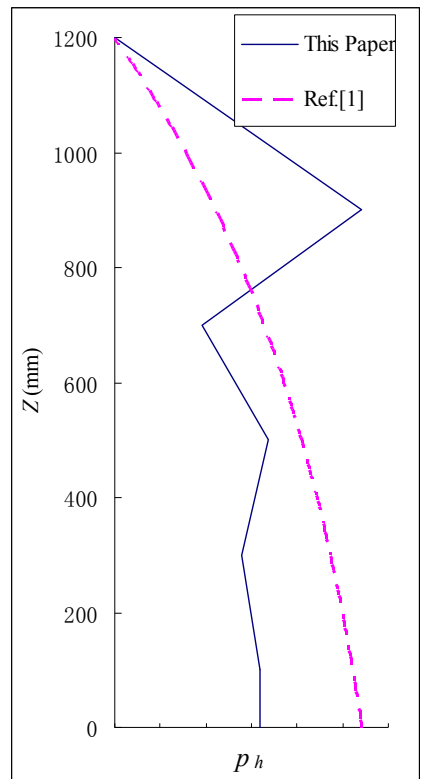

Figure 17. Comparison of the Loading Modes

\section{CONCLUSIONS}

In this paper, an experimental model of a double-wall steel insulation silo with multiple bolted joints is designed. An experiment is carried out to get its strain, deformation, horizontal pressure, ultimate bearing capacity and failure mode. The experiment plan and results may shed light on future studies of steel insulation silo. Based on the experimental and numerical study, the following conclusions can be drawn: 
1) The cooperation between the internal and external walls is outstanding. Among the six proposed models, A3, A4 and A5 present almost the same results during the whole loading process. Their strain, deformation, failure mode are consistent with those of the experiment, indicating they are all reasonable connection models. A3 is recommended due to its simplicity in modeling and calculation.

2) The pattern of resisting the horizontal pressure keeps unchanged during the loading process, where the horizontal pressure is mainly resisted by the internal wall under tension while the external wall does not resist much of the pressure.

3) Before the force $P$ reaches $P_{u-i n}$, the pattern of carrying the vertical friction force remains the same, where the vertical friction force is carried by both the internal and external walls. When the force $\mathrm{P}$ reaches $\mathrm{P}_{\mathrm{u} \text {-in, }}$ a sudden elastic-plastic buckling of the internal wall at the area between the first external ring beam and the supports sharply decreases its capacity of carrying the vertical friction force. After that, the external wall bears more and more vertical friction force, then it also shows an elastic-plastic buckling at the same area. Finally, the walls at this area are destroyed and the model loses the bearing capability.

\section{ACKNOWLEGEMENTS}

The presented work was supported by the National Natural Science Foundation of China (NO.51008067), NUAA Research Funding (NO.NS2010018), Jiangsu provincial Six Talent Peaks (NO.2010-JZ-007) and the Priority Academic Program Development (PAPD) of Jiangsu Higher Education Institutions.

\section{REFERENCES}

[1] Yin, L.F, Tang, G., Guo, X.M. and Lai, H.B., "Research on a New Double-Wall Steel Insulation Silo with Multiple Bolted Joints: Part I, Structure System”. Advaced Steel Construction, 2013, Vol. 9, No. 4, pp. 369-382.

[2] Brown, C.J., Lahlouh, E.H. and Rotter, J.M., "Experiments on a Square Planform Silo", Chem Engng Sci., 2000, Vol. 55, No. 20, pp. 4399-4413.

[3] Tejchman, J. and Ummenhofer, T., "Bedding Effects in Bulk Solids in Silos: Experiments and a Polar Hypoplastic Approach", Thin-Walled Structures, 2000, Vol.37, pp.333-361.

[4] Zhao, Y. and Teng, J.G., "Buckling Experiments on Steel Silo Transition Junctions, I: Experimental Results", Journal of Constructional Steel Research, 2004, Vol. 60, pp. 1783-1801.

[5] Zhao, Y. and Teng, J.G., "Buckling Experiments on Steel Silo Transition Junctions. II: Finite Element Modeling”, Journal of Constructional Steel Research, 2004, Vol. 60, pp.1803-1823.

[6] Ying, G.S. and Huang, Y., "An Experimental Study on the Vibration Characteristics of Thin-walled Silo Models", Journal of Experimental Mechanics, 2002, Vol. 17, No. 2, pp. 191-199. (in Chinese)

[7] Zhang, C. and Shu, G.P., "Experimental Research of Ground-supported Steel Silo Model's Discharge", Journal of Southeast University (Natural Science Edition), 2009, Vol. 39, No. 3, pp. 531-535. (in Chinese) 